\title{
Electricity efficiency of auxiliary power systems in coal thermal power plant
}

Case study

\author{
Azrina Mujanović \\ University of Tuzla \\ Faculty of Electrical Engineering \\ Franjevačka 2, Tuzla, Bosnia and Herzegovina \\ e-mail: azrina.avdic@fet.ba

\section{Tatjana Konjić} \\ University of Tuzla \\ Faculty of Electrical Engineering \\ Franjevačka 2, Tuzla, Bosnia and Herzegovina \\ e-mail: tatjana.konjic@fet.ba
}

\author{
Adisa Dedić \\ University of Tuzla \\ Faculty of Electrical Engineering \\ Franjevačka 2, Tuzla, Bosnia and Herzegovina \\ e-mail:adisa.dzanic@fet.ba
}

\begin{abstract}
Renewable energy sources such as hydro, wind and solar energy are taking an increasing share in the electricity mix. However, electricity production from thermal power plants is independent of the weather conditions and is still important as a backup power source to renewable energy sources. Given the fact that the electricity market is open, it is clear that each MWh is important. Therefore, auxiliary power systems as a part of thermal power plants should be also energy efficient. The main aim of the presented research was to investigate the efficient operation of different consumers in the auxiliary power system in the old-dated thermal power plant "Tuzla" depending on different power at generator output. The performed analysis identified consumers suitable for electricity efficiency improvement giving results of power savings obtained on modestly available measurements and old-date technical documentation. Following obtained results, some recommendations for improving electricity efficiency were proposed with a rough calculation of possible savings. Measurements of auxiliary power system consumption depending on power at generator output in new thermal power plant "Stanari" was presented. Future trends and directions in thermal power plant automation were also discussed.
\end{abstract}

Keywords - auxiliary power systems, energy efficiency, thermal power plants

\section{INTRODUCTION}

Economic and environmental requirements present a significant challenge for the industry in the last few years. The main driving factors for investing in operational cost and capital costs are increasing environmental standards and competition in the global market.

In recent years, the global energy sector is undergoing major change and transition. The change is primarily caused by global clean energy policies and the rapid development of new technologies that become more commercially available.

Members of EU as well as countries from West Balkan Region are faced with great decisions, challenges and uncertainties related to energy context in the future period. Western Balkan countries should fully implement the standards agreed in Paris in 2015 and start to make plans for the decarbonization of the energy sector [1].

Large global coal reserves mean that coal will have an important role in the energy transition. During this period, the security of electricity supply and the sophisticated use of coal will be crucial. Therefore, it is necessary to decide which power plants should be closed, which revitalized, and which build.

In most fossil fuel power plants, $7-15 \%$ of the produced energy on the generator does not reach the util- 
ity grid because it is geared back to pumps, fans, and other auxiliary power systems [2], [3].

In the process of electricity generation, many electric motors operate at $6 \mathrm{kV}$ and drive various consumers, such as fans, pumps, belt conveyors, various mills, etc. These consumers make auxiliary power systems of thermal power plant (TPP). The auxiliary power systems ensure the steam cycle circulates securely and returns to the thermodynamic starting point. The steam cycle would suffer unsustainable expansion or direct collapse without the auxiliary power system. Preserving the projected shape of the steam-water cycle, in a wide range of operating conditions, using minimum energy and with maximum availability, is the main purpose of auxiliary power systems in thermal power plants.

Auxiliary power systems (APS) of old-dated thermal power plants are over-invested and not energy efficient because at that moment production and reliability were only important. However, nowadays the electricity market is open and each MWh is important.

Concerning the global energy scene, Indian researchers are addressing the issue of energy efficiency of auxiliary power systems in thermal power plants. Mandi and Yaragati presented an energy efficiency improvement of major consumers of auxiliary power systems with different plant load factors in [3]. The financial impact of saving in $1 \%$ of auxiliary power systems is presented by Agarwal in [4]. Mandi and Yaragatti wrote about factors responsible for the high consumption of auxiliary power systems and about energy conservation measures which consume auxiliary power systems in [5]. Mechanical measures for energy conservation in auxiliary power systems were presented by Mandi, Seetharamu and Yaragatti. Narayana in [6] and Bhatt have presented minimization of auxiliary power systems consumption in coal thermal power plants through operational optimizations pumps and fans, overhaul and repairs, simple modification, retrofitting and modernization in [7].

There are five thermal power plants in Bosnia and Herzegovina. Four of them are old-dated. In order to be competitive in the electricity market and to meet emissions requirements, they must be modernized. Recently, the problem of auxiliary power systems efficiency in the thermal power plants in Bosnia and Herzegovina has started to be taken more seriously. As a result, the first works about energy efficiency in thermal power plants in Bosnia and Herzegovina emerged. The importance of energy efficiency in thermal power plants was discussed in the paper written in 2017 by Milovanovic, Samardzic, Babic and Dumonjic-Milovanovic [8]. The cost-effectiveness analysis of modern technology application in the auxiliary power system in the coal TPP "Kakanj" was presented by Lujnovic, Dacic-Lepara and Terzo in [9].

In this paper, APS of the coal TPP „Tuzla", Bosnia and Herzegovina, is presented. The aim was to identify main consumers in APS, analyze their operation related to generator output, identified possible savings and proposed some solutions for electricity efficiency improvement.

The paper is organized as follows. In section 2 methodology approach for analysis of auxiliary power systems in TPP „Tuzla“ - Unit 5 is explained. Proposed analysis and obtained results of fresh air fans, flue gas fans and cooling water pumps operation at different powers of the generator output are given in Section 3. In Section 4 solution for observed consumers, control is presented as well as the example of auxiliary power systems in advanced thermal power plants "Stanari" in Bosnia and Herzegovina. Summaries of the presented research and analysis with future directions of automation in TPP"Tuzla" are given in Section 5.

\section{METHODOLOGY APPROACH}

Nowadays, energy efficiency is an important part of any technological process. As it is mentioned above 7-15\% of generated electricity in TPP has been used by auxiliary power systems [2], [3]. These percentages indicate space for electricity efficiency analysis and the possibility of efficiency improvement.

The subject of our analysis is auxiliary power systems of Unit 5 in TPP "Tuzla", dated from 1974. The nominal power of Unit 5 -TPP "Tuzla" is $200 \mathrm{MW}$. The technology used to control auxiliary power systems in the unit is outdated and mainly mechanically control. The methodology approach consists of several steps.

The first step of the energy analysis was energy audit of Unit 5 of the thermal power plant with special emphasis on its auxiliary power systems, discussions with employees and identifying consumers of interest for improving electricity efficiency.

Consumers of the auxiliary power systems in TPP "Tuzla" are shown in Table 1.

Table 1. Structure of the auxiliary power systems in TPP „Tuzla“

\begin{tabular}{|ccc|}
\hline Consumers & $\begin{array}{c}\text { Number of } \\
\text { consumers }\end{array}$ & $\begin{array}{c}\text { Nominal power } \\
(\mathbf{k W})\end{array}$ \\
\hline Conveyors & 2 & $2 \times 160=320$ \\
\hline Excavator pumps & 4 & $4 \times 200=800$ \\
\hline Mills & 8 & $8 \times 500=4000$ \\
\hline Fresh air fans & 3 & $3 \times 500=1500$ \\
\hline Flue gas fans & 3 & $3 \times 1000=3000$ \\
\hline Oil dispensing pump & 1 & 200 \\
\hline Condensate pumps & 3 & $200+2 \times 250=700$ \\
\hline Feed water pumps & 3 & $3 \times 3150=9450$ \\
\hline Cooling water pumps & 2 & $2 \times 1000=2000$ \\
\hline Total nominal power & & $\mathbf{2 1 6 5 0}$ \\
\hline
\end{tabular}

All of these consumers have been mechanically controlled. The energy consumption of fans and pumps is 
proportional to the third gear speed. This ratio brings great energy savings, even at modest speed reductions and favors designs that seek to reduce speeds, such as using variable speed drives. Therefore, these consumers are interesting in efficiency analysis.

The second step is data collection. Given the fact that Unit 5 is old-dated, technical documentation has been mainly lost and the unit is not equipped by modern monitoring systems, it is difficult to get needed information for detailed efficiency analysis of auxiliary power systems.

Deficiency identification related to availability and existence of needed data for analysis as well as an adequate supporting measurement system presents an important step in whole analysis.

The most important data for electricity efficiency analysis is consumer load. The existing monitoring system in TPP „Tuzla" - Unit 5 does not provide consumer load data. The existing monitoring system provides information about the consumer's currents, flows and positions of the control bodies.

Following collected information about existing documentation and available data, the possible methods of analysis were proposed that present the next step in the methodology. The consumer load needed for calculation will be obtained combining measurements of current and curves $I=f(P)$ from available technical documentation. Flows and positions of the control bodies allow calculation of the needed power for achieving the required flow.

Obtained results in the previous step will help to propose a possible solution for improving the electricity efficiency of the observed consumers in the auxiliary power systems. Justification of possible solution implementation will be confirmed by the calculation of power and money savings.

\section{ANALYSIS AND RESULTS}

In this section electricity analysis and results of chosen consumers in auxiliary power systems are presented. Based on data from the existing monitoring system, technical documentation and the fact that the power consumption of pumps and fans is proportional to the third gear consumers chosen for analysis are fresh air fans, flue gas fans and cooling water pumps. In addition to these consumers, it would be important to analyze feed water and condensate pumps. Unfortunately, the existing monitoring system and technical documentation do not provide all the needed data for calculation. The analysis was done for two different powers of the generator output (Unit 5). Analysis of APS total power when the generator shuts down (the major changes in the power of the generator output) is also presented in the section.

\subsection{THE FRESH AIR FANS AT DIFFERENT POWERS OF THE GENERATOR OUTPUT}

As can be seen from Table 1 there are three fresh air fans (FAF). The fresh air fans are the same characteristics. Therefore, detailed analysis and calculation will be presented only for one FAF.

Needed data for an analysis of the fresh air fan operation are developed power on the fresh air fan motor, the airflow through the fan, and the position of the control blades. The existing monitoring system provides data about the current of each fan motor, the position of the control blades, as well as the airflow through the fresh air fan. Power developed on the motor can be obtained from the characteristic $P_{1}=f\left(I_{1}\right)$, where:

- $\quad \mathrm{P}_{1}$ - motor power and

- $\mathrm{I}_{1}$ - motor current.

This characteristic is available in the technical documents from TPP "Tuzla" [10].

The first observation of the fresh air fan was done during generator operation near nominal power (200 MW).

Power at the generator output during the period 17:20 - 20:20 on July 2, 2016, is shown in Figure 1. Figure 2 shows small current variations of a fresh air fan in the same period. This was a relatively stable coal combustion period in accordance with information about coal quality during the observed period.

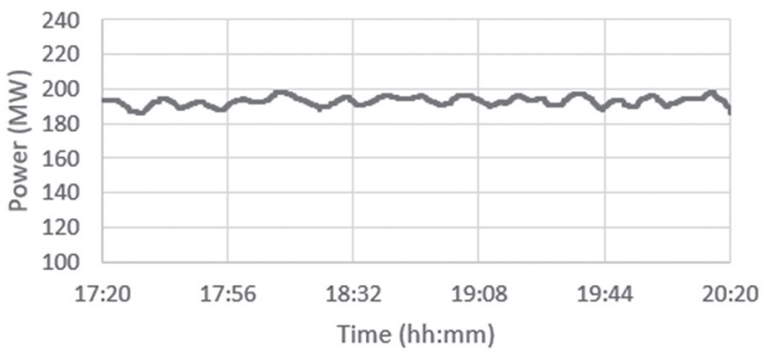

Fig. 1. Power of the generator output

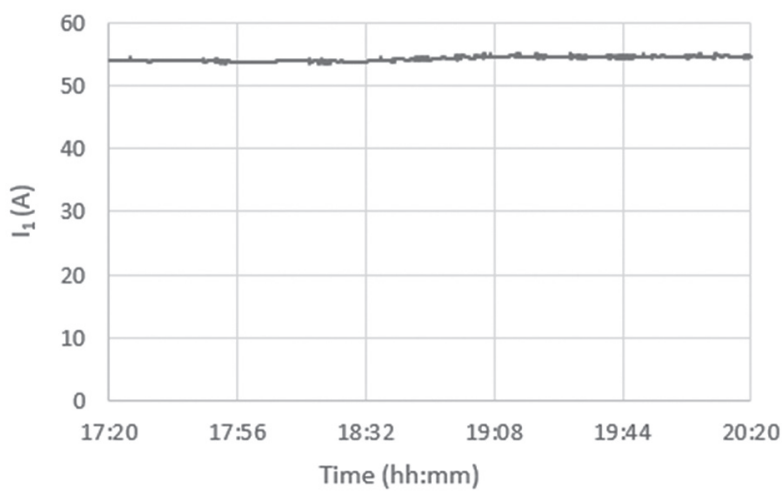

Fig. 2. Current of fresh air fan when the power of generator output is about $195 \mathrm{MW}$

The connection between motor power $\mathrm{P}_{1}$, current $\mathrm{I}_{1}$ and power factor is given by characteristics $I_{1}=f\left(P_{1}\right)$ and $\cos \Phi=f\left(P_{1}\right)$. The curves are shown in Figure 3 . 


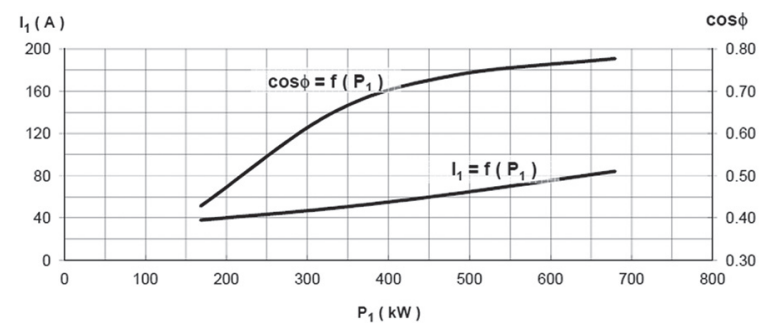

Fig. 3. $l_{1}=f\left(P_{1}\right)$ and $\cos \Phi=f\left(P_{1}\right)$ for the motor of $a$ fresh air fan [10]

It can be noticed from Figure 2 that for the current of $54 \mathrm{~A}$ the motor power $\mathrm{P}_{1}$ is about $380 \mathrm{~kW}$ and $\cos \Phi$ is about 0.69 . FAF nominal power $P_{n}$ is $500 \mathrm{~kW}$ and 380 kW presents $60 \% P_{n}$.

Airflow through FAF and the control blade position are shown in Figure 4 and Figure 5, respectively.

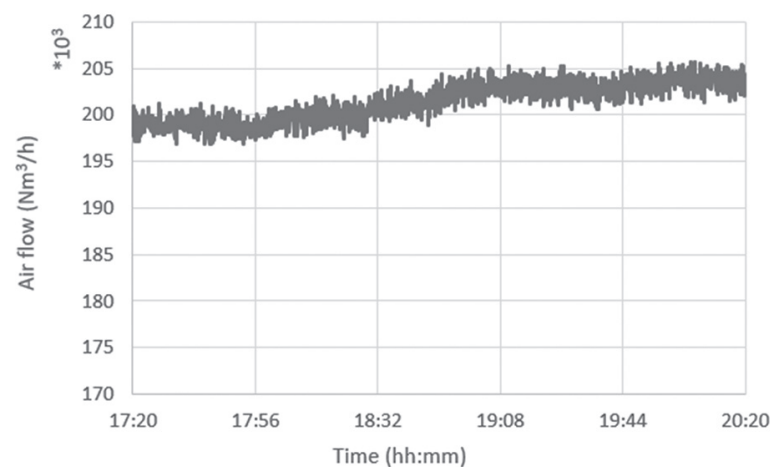

Fig. 4. Airflow through the fresh air fan

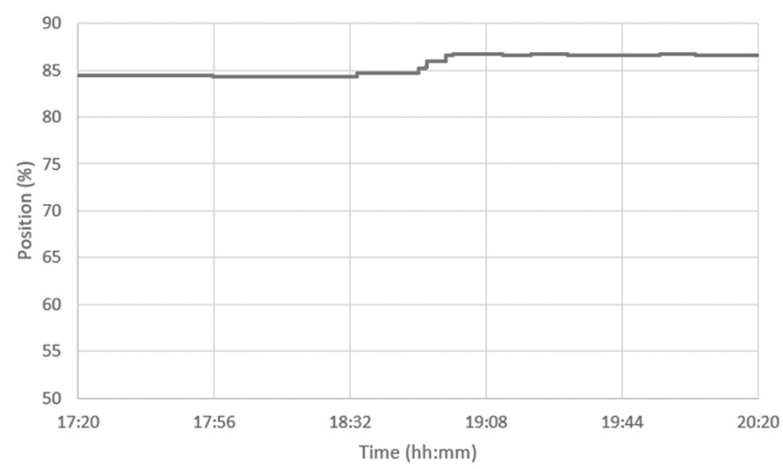

Fig. 5. Control blade position of the fresh air fan

According to diagrams presented in Figures 4 and 5, the control blade is opened about $85 \%$ and the airflow is about $204000 \mathrm{~m}^{3} / \mathrm{h}$ that presents $68 \%$ of the maximum flow $\left(300000 \mathrm{~m}^{3} / \mathrm{h}\right)$ at maximum fan load. Considering the fact that the flow is proportional to the motor speed

$$
\frac{Q}{Q_{n}}=\frac{N}{N_{n}}
$$

where

- $\mathrm{Q}$ - needed flow,

- $\mathrm{N}$ - needed motor speed,
- $Q_{n}-$ nominal flow,

- $\quad \mathrm{N}_{\mathrm{n}}$ - nominal motor speed,

it can be concluded that such a flow can be achieved by reducing the motor speed to $68 \%$ of the nominal speed. The nominal motor speed is 594 RPM.

The connection between power and motor speed of FAF is

$$
\frac{P}{P_{n}}=\left(\frac{N}{N_{n}}\right)^{3},
$$

where $\mathrm{P}$ is needed power and $\mathrm{P}_{n}$ nominal power (500 $\mathrm{kW})$. Needed power to achieve the required flow is

$$
\frac{P}{P_{n}}=\left(\frac{0.68 N_{n}}{N_{n}}\right)^{3}
$$

$$
\frac{P}{P_{n}}=0.314=>P=0.314 P_{n} .
$$

Needed power is $157 \mathrm{~kW}$ in this case. From (4) it can be concluded that only $31.4 \%$ of the nominal motor power is needed to achieve the required flow.

Besides the presented analysis of FAF when the generator output was $195 \mathrm{MW}$, the same analysis and calculations were done at $165 \mathrm{MW}$ of the generator output (during period 23:20:58 - 23:28:56 on March 3, 2017). The summary of both calculations is given in Table 2 .

Table 2. Fresh air fan results of the electricity efficiency analysis at two different power of the generator output

\begin{tabular}{|ccc|}
\hline $\begin{array}{c}\text { Power of the } \\
\text { generator output }\end{array}$ & $195 \mathrm{MW}$ & $165 \mathrm{MW}$ \\
\hline $\begin{array}{c}\text { Current of FAF } \\
\begin{array}{c}\text { Estimated motor } \\
\text { power }\end{array}\end{array}$ & $54 \mathrm{~A}$ & $54 \mathrm{~A}$ \\
\hline Air flow & $204000 \mathrm{Nm}^{3} / \mathrm{h}(68 \%)$ & $177000 \mathrm{Nm}^{3} / \mathrm{h}(59 \%)$ \\
\hline $\begin{array}{c}\text { Position of the } \\
\text { control blade }\end{array}$ & $85 \%$ & $67 \%$ \\
\hline $\begin{array}{c}\text { Needed motor } \\
\text { power }\end{array}$ & $31.4 \% \mathrm{P}_{\mathrm{n}}=157 \mathrm{~kW}$ & $21 \% \mathrm{P}_{\mathrm{n}}=105 \mathrm{~kW}$ \\
\hline
\end{tabular}

\subsection{THE FLUE GAS FANS AT DIFFERENT POWERS OF THE GENERATOR OUTPUT}

The auxiliary power systems in TPP "Tuzla" contain three same flue gas fan (FGF) of $1000 \mathrm{~kW}$. These three fans haven't the same load. The first fan has the highest load. The second and third flue gas fans have the same load (slightly lower). As in previous analysis, it is needed to know the developed power on the flue gas fan motor, the gas flow through the fan, and the position of the control blades. The existing monitoring system provides data about current and the control blades position of each fan. Unlike the previous analysis, the flow of gas through the fans is not monitored. Therefore, it 
is necessary to presume flow based on the maximum flow $\left(720000 \mathrm{Nm}^{3} / \mathrm{h}\right)$ and the position of the control blades (for example: if the position of the control blade is $50 \%$, presumed flow is $360000 \mathrm{Nm}^{3} / \mathrm{h}$ ).

According to the presented analysis of FAF, the same analysis of FGF based on $I_{1}=f\left(P_{1}\right)$ characteristics, presumed airflow and control blade position, as well as calculations based on equations (1)-(4), was done. Summary of calculation for the first FGF is given in Table 3 while the summary for the second (the third) FGF is presented in Table 4. Taken into consideration that the load of the third fan is the same as the load of the second fan and that the characteristics of all three flue gas fans are the same, it is not necessary to show the analysis of the third flue gas fan.

Table 3. The first flue gas fan results of the electricity efficiency analysis at two different powers of the generator output

\begin{tabular}{|ccc|}
\hline Generator power & $195 \mathrm{MW}$ & $165 \mathrm{MW}$ \\
\hline Current of FGF & $80 \mathrm{~A}$ & $79 \mathrm{~A}$ \\
\hline $\begin{array}{c}\text { Estimated motor } \\
\text { power }\end{array}$ & $580 \mathrm{~kW}(58 \% \mathrm{Pn})$ & $580 \mathrm{~kW}(58 \% \mathrm{Pn})$ \\
\hline $\begin{array}{c}\text { Estimated air flow } \\
\text { Position of control } \\
\text { blade }\end{array}$ & $360000 \mathrm{Nm}^{3} / \mathrm{h}(50 \%)$ & $324000 \mathrm{Nm}^{3} / \mathrm{h}(45 \%)$ \\
\hline $\begin{array}{c}\text { Needed motor } \\
\text { power }\end{array}$ & $12.5 \% \mathrm{P}_{\mathrm{n}}=125 \mathrm{~kW}$ & $95 \%$ \\
\hline
\end{tabular}

Table 4. The second flue gas fan results of the efficiency analysis at two different powers of the generator output

\begin{tabular}{|ccc|}
\hline $\begin{array}{c}\text { Power of the } \\
\text { generator output }\end{array}$ & $195 \mathrm{MW}$ & $165 \mathrm{MW}$ \\
\hline $\begin{array}{c}\text { Current of FGF } \\
\text { Estimated motor } \\
\text { power }\end{array}$ & $380 \mathrm{~kW}(38 \% \mathrm{Pn})$ & $380 \mathrm{~kW}(38 \% \mathrm{Pn})$ \\
\hline $\begin{array}{c}\text { Estimated air flow } \\
\text { Position of control } \\
\text { blade }\end{array}$ & $345600 \mathrm{Nm}^{3} / \mathrm{h}(48 \%)$ & $309600 \mathrm{Nm}^{3} / \mathrm{h}(45 \%)$ \\
\hline $\begin{array}{c}\text { Needed motor } \\
\text { power }\end{array}$ & $48 \%$ & $43 \%$ \\
\hline
\end{tabular}

It is important to note that the analysis for the flue gas fans was carried out with the assumed flow based on the maximum flow and position of the blades.

\subsection{THE COOLING WATER PUMPS AT DIFFERENT POWERS OF THE GENERATOR OUTPUT}

The auxiliary power systems in TPP "Tuzla" contain two same cooling water pumps of 1000 kW. Needed data for the analysis of the cooling water pumps operation are the developed power on the cooling water pumps motor, the flows through the pumps, and the position of the valves.
The existing monitoring system provides data about the current and the position of the valves. Data about flows through pumps are not provided by the existing monitoring system. It is enough to show up the analysis for one pump because the pumps are symmetrically loaded and have the same characteristics. Table 5 shows the current, estimated power and position of the cooling water pump valve for different powers at the generator output.

Table 5. Results of electricity efficiency analysis for the cooling water pump at two different powers of the generator output

\begin{tabular}{|ccc|}
\hline Generator power & $195 \mathrm{MW}$ & $165 \mathrm{MW}$ \\
\hline $\begin{array}{c}\text { The current of } \\
\text { cooling water pump }\end{array}$ & $108 \mathrm{~A}$ & $108 \mathrm{~A}$ \\
\hline Estimated power & $87 \% \mathrm{P}_{\mathrm{n}}$ & $87 \% \mathrm{P}_{\mathrm{n}}$ \\
\hline Position of the valve & $100 \%$ & $100 \%$ \\
\hline
\end{tabular}

It can be noticed that the change of power at the generator output doesn't change the load and valve position of the observed cooling water pumps.

\subsection{ANALYSIS OF THE TOTAL POWER OF AUXILIARY POWER SYSTEMS}

The power of the auxiliary power system is about 16 MW, which is about 74\% of the projected power of auxiliary power systems. The projected power of auxiliary power systems, from Table 1, is 21.65 MW (4.7 MW occupying backup consumers). Due to mechanical control, it is assumed that with significant changes in the power at the generator output the power of own consumption does not change. It means, reducing the power at the generator output, the rate of APS total power in the power of the generator output will increase.

Figure 6 shows the power at the generator output when the generator goes out of the work (shuts down), while Figure 7 shows the power of auxiliary power systems during the same period.

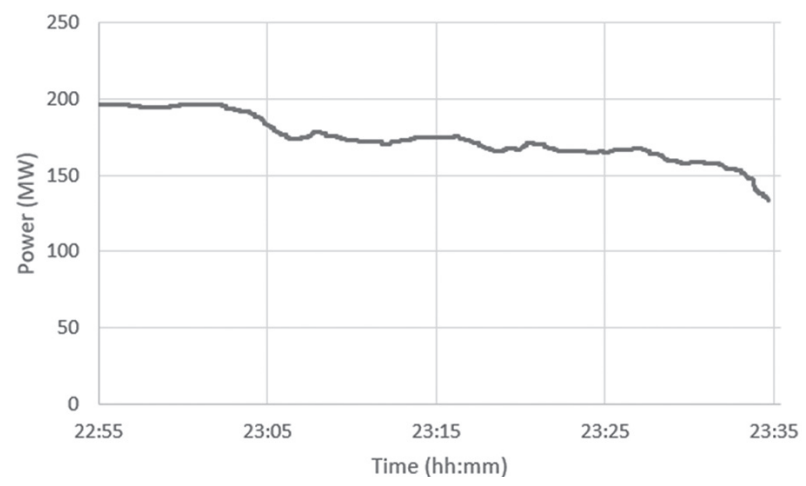

Fig. 6. Power of the generator output when the generator goes out of work (shuts down) 


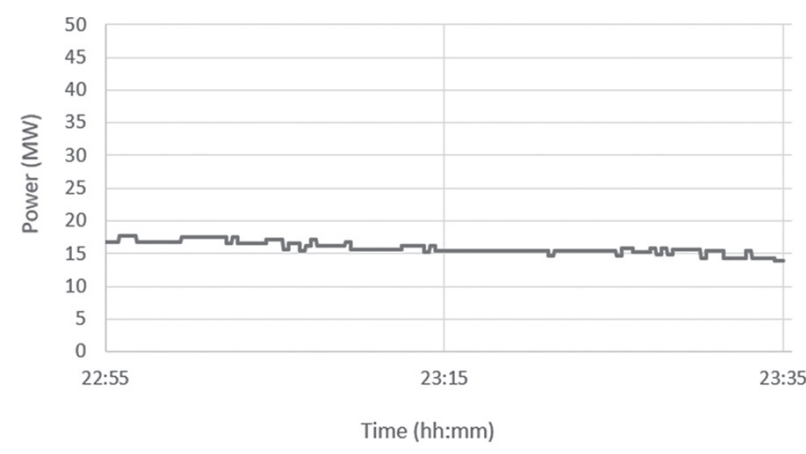

Fig. 7. Total power of the auxiliary power systems when the generator goes out of work (shuts down)

From Figures 6 and 7 it can be noticed that significant changes of power at the generator output do not cause significant changes in the power of the auxiliary power systems. Namely, with the change of power at the generator output, there is a change in the position of control blades and valves on consumers, whereby the load of consumers doesn't change.

\section{PROPOSED SOLUTION}

Improvements in the auxiliary power system control are important and result in lower electricity consumption for electricity production, which will provide ie. higher amount of energy that can be sold for the same amount of input fuel. In this section solution for improvement in the operation of observed consumers was presented with rough calculations of power and money savings. An example of efficient APS operation is presented on the new thermal power plant "Stanari" (Bosnia and Herzegovina).

\subsection{THE PROPOSED SOLUTION FOR OBSERVED CONSUMERS IN AN AUXILIARY POWER SYSTEM IN TPP „TUZLA“ - UNIT 5}

As it can be seen from Table 2, Table 3 and Table 4, when the power of the generator output is changed, the current of the fresh air fan and flue gas fan remains the same, because the control is achieved mechanically (by blades). This problem can be solved by installing a frequency converter. Installation of the frequency converter justifies the fact that the generator of Unit 5 doesn't always work with nominal power, due to power system requirements. The obtained results of the analysis indicate that the use of a frequency converter could make great savings. Rough estimations of power savings for the observed FAFs and FGFs in both cases at different power of the generator output are shown in Table 6 .

Total savings for $3 \mathrm{FAFs}$ plus $3 \mathrm{FGFs}$ is $3.684 \mathrm{MW}$ at 195 MW and $3.933 \mathrm{MW}$ at $165 \mathrm{MW}$ of generator output.

The power of the generator output varies from 140 MW to $200 \mathrm{MW}$. The technical minimum of the generator operation is $140 \mathrm{MW}$, but usually, the output of the generator does not go below $145 \mathrm{MW}$. According to obtained results in Table 6 and applied approximation, it is possible to identify the range of savings for these six consumers from 3.6 MW to 4.1 MW.

The price of electricity is very variable and changes to the hourly level. Thermal power plant "Tuzla" operates on the Hungarian Power Exchange. Based on data from https://hupx.hu/en/market-data/dam/historicaldata, the range for electricity price is very large. From the beginning of 2020, the minimum electricity price was $11,21 € / \mathrm{MWh}$, and the maximum was $104.62 € / \mathrm{MWh}$. The mean electricity price from the beginning of 2020 is about $55 € / M W h$.

Money savings will be obtained multiplying power savings and electricity prices. Money savings for one hour of the unit operation, in the case of the mean electricity price of about $55 € / M W h$ are shown in Table 7 .

Table 6. Power savings that would be achieved by installing frequency converters on 3 FAFs and 3 FGFs

\begin{tabular}{|c|c|c|c|}
\hline $\begin{array}{c}\text { Power } \\
\text { of the } \\
\text { generator }\end{array}$ & & FAFs & FGFs \\
\hline \multirow{3}{*}{$195 \mathrm{MW}$} & $\begin{array}{l}\text { Nominal power } \\
(\mathrm{kW})\end{array}$ & $3 \cdot 500=1500$ & $\begin{array}{l}1 \cdot 1000=1000 \\
2 \cdot 1000=2000\end{array}$ \\
\hline & $\begin{array}{l}\text { Needed Power } \\
(\mathrm{kW})\end{array}$ & $3 \cdot 157=471$ & $\begin{array}{l}1 \cdot 125=125 \\
2 \cdot 110=220\end{array}$ \\
\hline & $\begin{array}{l}\text { Power savings } \\
\text { (kW) }\end{array}$ & $3 \cdot 343=1029$ & $\begin{array}{c}1 \cdot 875=\mathbf{8 7 5} \\
2 \cdot 890=\mathbf{1 7 8 0}\end{array}$ \\
\hline \multirow{3}{*}{$165 \mathrm{MW}$} & $\begin{array}{l}\text { Nominal power } \\
\text { (kW) }\end{array}$ & $3 \cdot 500=1500$ & $\begin{array}{l}1 \cdot 1000=1000 \\
2 \cdot 1000=2000\end{array}$ \\
\hline & $\begin{array}{l}\text { Needed power } \\
\qquad(\mathrm{kW})\end{array}$ & $3 \cdot 105=315$ & $\begin{array}{c}1 \cdot 92=92 \\
2 \cdot 80=160\end{array}$ \\
\hline & $\begin{array}{l}\text { Power savings } \\
\text { (kW) }\end{array}$ & $3 \cdot 395=1185$ & $\begin{aligned} 1.908 & =\mathbf{9 0 8} \\
2.920 & =\mathbf{1 8 4 0}\end{aligned}$ \\
\hline
\end{tabular}

Table 7. Money savings at the bases of one hour for $3 \mathrm{FAFs}$ plus $3 \mathrm{FGFs}$

$\begin{array}{ccc}\text { Power of the generator output } & \text { 3 FAF } & \text { 3 FGF } \\ \mathbf{1 9 5} \text { MW } & 56.60 € & 146 € \\ \mathbf{1 6 5} \text { MW } & 65.17 € & 151.14 €\end{array}$

To calculate the annual savings, the number of operating hours of Unit 5 is required. Regular overhaul (30 days) and planned and unplanned downtime due to boiler failures, good hydrology, etc. (30 days) are taken into account. Therefore, the number of operating hours is about 7300 . Annually savings will be obtained multiplying power savings for one hour, electricity price and the number of operating hours. Annually savings for three fresh air fans plus three flue gas fans are presented in Table 8. 
Table 8. Annually money savings for 3 FAFs plus 3 FGFs

\begin{tabular}{|cc|}
\hline Power of the generator output & 3 FAF + 3 FGF \\
\hline $\mathbf{1 9 5} \mathbf{~ M W}$ & $1.479 .126 €$ \\
$\mathbf{1 6 5} \mathbf{~ M W}$ & $1.579 .099 .5 €$ \\
\hline
\end{tabular}

According to the possible variation of power savings for all six consumers between 3.6 MW and 4.1 MW, annual money savings will vary in range from $1445400 €$ to $1646150 €$.

To accurately determine the savings and payback period of an investment, a detailed and serious costbenefit analysis is required, which requires many other parameters such as presented in [9]. According to experiences in TPP "Tuzla" on recovering similar investments made on other units, the estimated pay-back period is less than 10 years (seven to ten years).

As far as the cooling water pump, the use of frequency control in this drive is not required, because the valve position doesn't change. Also, the motor observed cooling water pump is not overloaded. Namely, regarding the flow control of the cooling water pumps, the pumps have valves that are always maximally (100\%) open. Therefore, there is no flow variation on the cooling water pumps resulting from a change in the position of an executive body. Pump valves are always maximally open because it is always necessary to have the same cooling water flow that cools the condenser (cooling system requirements).

A poor performing cold end cycle is the problem of many existing thermal power plants. Key components of this cycle are low-pressure turbine, the condenser or the cooling tower. The reduced performance can be caused by multiple factors such as a poor initial design, an imbalanced system with new and old equipment, the natural degradation of components or by external factors (control and environmental changes). To resolve this situation evaluation of the whole power plant, or more specifically on the cold end cycle is needed.

All operations for revitalize an auxiliary power system and introduce automation can be done during a regular capital overhaul (90 days). Theoretically, it could be done within 30 days if pre-fabricated factory modules are installed, but due to regular maintenance activities and subsequent functional tests, a regular 30-day overhaul is not a realistic timeframe.

The use of a quality energy management system for thermal power plants is very important. The concept and philosophy of energy management approach in order to improve the performance indicators are written by Vinchurkar, Lakhe, Shrivastava in [11]. These authors also wrote about focuses on energy management practices followed in thermal power plants to identify the areas for improvement of energy efficiency of the plant in [12]. Objectives of energy management system in thermal power plants are increasing plant performance (availability factor and plant load factor) and reduction specific oil consumption, auxiliary power systems consumption and gross plant heat rate. Very profitable would be an integrated management system for thermal power plants with the electrical control system for real-time data which would respond to the current needs for better coordination and operational decisions. A distributed control system with an integrated electrical control system for thermal power plant and electrical distribution network would help plant managers to manage production efficiently. This would provide power system stability and process continuity. Also, the integrated control system would provide all advanced tools which would allow electrical power users and producers to be more reliable and put operators and engineers in control of the operation, maintenance and planning of the thermal power plant and electrical power system. This would result in optimum system usage, financial stability and lower costs. Advanced features EMS/DMS online system allow more precise control of the drive and online profit calculations through comparison with the current price on the stock market from the economic side.

Future trends and directions in thermal power plant automation is the implementation of the big data concept. It will be possible to send data to IT Cloud and compare performance (efficiency, technological parameters, etc.) of similar thermal power plants worldwide. This will give the possibility of predictive maintenance and reducing downtime plants through the elimination of the need for periodic inspections and reducing unplanned downtime to a minimum.

\subsection{EXAMPLE OF ADVANCED AUXILIARY POWER SYSTEMS IN TPP „STANARI“}

Advanced thermal power plants are expected to be flexible, due to renewable energy sources. Therefore, the expectation is that the auxiliary power system as a part of TPP would be flexible too. It means when generator power is decreased, the power of the auxiliary power system should be reduced. The thermal power plant "Stanari" is an advanced thermal power plant, located near the coal mine "Stanari" in the north of Bosnia and Herzegovina.

The nominal power of TPP "Stanari" is $300 \mathrm{MW}$. Thermal efficiency of TPP "Stanari" is 0.34 [13]. Two technical aspects that TPP "Stanari" distinguishes from similar coal thermal power plants in the region are combustion in a circulating fluidized bed and air-cooled condenser.

Primary and secondary fresh air fans, flue gas fans, feedwater pumps and condensate pumps are larger consumers in auxiliary power systems. Only feedwater pumps are controlled by a hydraulic coupler, and the control of other major consumers is done by cascading medium-voltage frequency converters. More information about auxiliary power systems in TPP "Stanari", as well as analysis of interesting consumers, are presented in [14] by Avdic, Konjic and Dautbasic. 
In this paper, it is only presented what happens with a total power of auxiliary power systems when generator power has small changes.

Figure 8 shows power at the generator output in the period from 01.03.2017. to 07.03.2017.

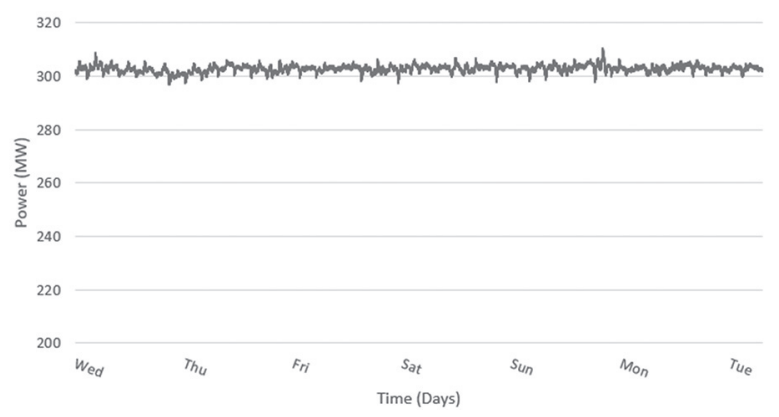

Fig. 8. Power of the generator output

Figure 9 shows the total power of auxiliary power systems in the same period from 01.03.2017 to 07.03.2017.

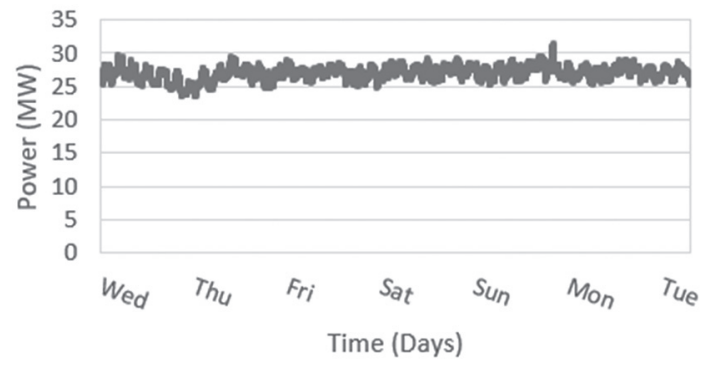

Fig. 9. Total power of auxiliary power systems

From Figure 8 and Figure 9 it can be noticed that even a small change of generator power causes a change of total power of auxiliary power systems in TPP "Stanari". This is the result of the frequent converter implementation to each major consumer of auxiliary power systems in TPP "Stanari". The projected power of the auxiliary power systems in TPP "Stanari" is about 54 MW. Besides previously mentioned, it also can be noticed that if the power of the generator's output is closed to nominal, the power of the auxiliary power system is about $27 \mathrm{MW}$. That is half of the projected power. Use of the frequency converter and other energy efficiency measures, the total power of the auxiliary power systems is reduced by $50 \%$. It is important to note that some consumers in auxiliary power systems are spare. They have not been in operation during the time the total power of the auxiliary power systems is observed.

\section{SUMMARY}

Nowadays electricity producers have worked on a market that has become increasingly demanding. Business pressure from market liberalization and fuel price increase requires from each producer to establish a more efficient way of converting as much as possible energy from fuel to electricity that can be sold. The electricity market is open and the result is a competition. It is important to produce electricity at a price that is competitive and acceptable on the market. In other words, every MWh is important.

Auxiliary power systems consumers, such as pumps and fans, that use constant motor speed and limit flow for control, spend more power when working with partial load. Electricity requirements vary throughout the year, days and even hours. Even if TPP works on constant power, the required flow through the pumps and fans varies due to changes in ambient conditions or fuel quality. Due to these variations, there is a constant need for process control and equipment such as pumps and fans. The conventional mode of pumps and fans load control is purely mechanical (valves and blades). Therefore, motors often operate with reduced loads and decreased power factor, ie. increased losses.

The main aim of the presented research was to analyze APS in old dated TPP "Tuzla". APS consists of different consumers. The projected power of the observed auxiliary power systems is $21,65 \mathrm{MW}$. Due to lack of all needed data for detailed analysis and advanced measurement systems, possible rough analysis based on technical documentation and some monitoring and archiving data was applied on fresh air fans, flue gas fans, and cooling water pumps.

In accordance with conducted research, analysis and obtained results it can be concluded:

- depending on the power at the generator output the power of the observed consumer does not vary;

- $\quad$ significant changes of power at the generator output do not cause significant changes in the power of auxiliary power systems;

- fresh air fans and flue gas fans have mechanical control, which is inefficient, while pumps currently have no control (valves are always maximally (100\%) open);

- fresh air and flue gas fans are oversized and the demand for electricity varies even at the hourly level, it can be concluded that there is a potential for savings, which can be achieved by applying medium voltage frequency converter;

- $\quad$ possible power savings for six consumers (3 FAFs+3FGFs) varies from 3.6 MW to 4.1 MW depending on power variation at the generator output from $145 \mathrm{MW}$ to $200 \mathrm{MW}$;

- the use of frequency converters for fresh air fans and flue gas fans would result in annual money savings in the range from $1445400 €$ to $1646150 €$;

- currently, it is not necessary to install the frequency converter for cooling water pumps, but it would be good to do a detailed analysis of the 
pump in terms of system requirements and find out why valves are always maximally (100\%) open;

- detailed cost-benefit analysis requires data about the power of the generator on a yearly basis, the number of operating hours, the price of the frequency converters and accessories, overhauls, price of electricity predicted for a future period of interest, etc.;

- benefits of the frequency converter implementation in the TPP "Stanari" are: increased process efficiency, flexibility and availability through improved process control, increased power at the plant's threshold for the same amount of fuel, reduced maintenance costs and $\mathrm{CO} 2$ emissions;

- $\quad$ also, it would be very useful to improve the monitoring system on Unit 5, in order to carry out a more detailed analysis of all consumers and to identify places where energy is unnecessarily consumed;

Revitalization of existing auxiliary power systems in the old TPP "Tuzla", should certainly not be without the associated frequency converter. The use of frequency converters for auxiliary power systems of these plants can lead to significant energy savings and lower cost of production.

As for further research, it would be good to determine why the valves on the cooling water pumps are always maximally (100\%) and to analyze the operation of the feedwater pumps and the condensate pumps. Analysis of the feed water and condensate pumps could be done by installing mobile devices for power measurement. Also, a detailed cost-benefit analysis is required, which requires the information specified in the summary.

Based on all above mentioned, the main contribution of the paper could be recognized in the identification of missing data needed for accurate consumption analysis of APS consumers in TPP "Tuzla" indicating the need for modernization of monitoring and measurement system; in proposing a possible analysis of electricity efficiency of different APS consumers in the case of lack of some date; in the identification of APS consumers suitable for control by frequency converter; in the identification of power and money savings in the case of control implementation on some APS consumers and in recommending future research in TPP "Tuzla". This work could be guided for other old-dated TPP in Bosnia and Herzegovina and in the Region that are in similar conditions.

\section{ACKNOWLEDGMENT}

The authors would like to thank the management of the TPP "Tuzla" for data access and colleagues from the plant on sharing with us useful expert information.

\section{REFERENCES}

[1] Framework energy strategy of Bosnia and Herzegovina until 2035, http://www.mvteo.gov.ba/ data/Home/Dokumenti/Energetika/Framework_ Energy_Strategy_of_Bosnia_and_Herzegovina_ until_2035_ENG_FINAL....pdf (accessed: 2019)

[2] ABB, Power generation, „Energy Efficient Design of Auxiliary Systems in Fossil Fuel Power Plants", 2009.

[3] R. P. Mandi, U. R. Yaragatti, "Energy Efficiency Improvement of Auxiliary Power Equipment in Thermal Power Plant through Operational Optimization", 2012 IEEE International Conference on Power Electronics, Drives and Energy Systems, Bangalore, India 16-19 December 2012.

[4] S. Agarwal, „Financial impact of auxiliary power in thermal power plant", https://taxguru.in/finance/ financial-impact-auxiliary-power-thermal-powerplant.html, (accessed: 2020)

[5] R.P. Mandi, U.R. Yaragatti, “Energy audit of auxiliary power in a coal fired thermal power plant", Technological advances for new power generating units and for performance enhancement of present plants, Bangalore, India, 18-19 November 2010.

[6] R. P. Mandi, S. Seetharamu, U. R. Yaragatti, “Enhancing energy efficiency of auxiliary power system in a $210 \mathrm{MW}$ coal fired power plant through energy efficiency", 2010 5th International Conference on Industrial and Information Systems, India, 29 July1 August 2010.

[7] B. H. Narayana, M. S. Bhatt, "Minimization of auxiliary power consumption in coal fired thermal power stations", National power system conference, Indian institute of technology, Madras, 2730 December, 2004.

[8] Z. Milovanović, M. Samardžić, V. Babić, S. Dumonjić-Milovanović, "Energetska efikasnost termoenergetskih postrojenja, Faze i metodologija realizacije izrade Studije na primjeru RiTE Ugljavik instalisane snage 300 MW" (engl. "Energy efficiency of thermal power plants - phases and methodology for realization of the study on example of mine and thermal power plant ugljevik with installed power of $300 \mathrm{MW}^{\prime \prime}$ ), Naučno-stručni simpozijum Energetska efikasnost 2017, Banja Luka, 3-4 Novembar 2017, pp. 134 - 147. 
[9] A. Lujnović, S. Dacić-Lepara, M. Terzo, "Cost-benefit analysis of frequency regulated electrical drives application in thermal power plants - experiences from TPP Kakanj", Journal B\&H Electrical Engineering, Volume 11, January/December 2017, pp. 108-116.

[10] Technical documentation (fresh air fans, flue gas fans, cooling water pumps) of TPP „Tuzla“, 1976.

[11] A. G. Vinchurkar , Dr. R. R. Lakhe, Dr. R. L. Shrivastava, "Energy performance improvement of coal fired thermal power plant - case study approach", International Journal of Advance Engineering and Research Development, Volume 1, Issue 11, 2014, pp. 237-250.

[12] A. G. Vinchurkar , Dr. R R Lakhe , Dr. R. L. Shrivastava, “Energy Management Approach To Improve
Performance Of Thermal Power Plant", International Journal of Engineering Research and Development, Volume 11, Issue 11, 2015, pp. 63-80.

[13] D. Miljević, M. Mumović, J. Kopač, Analysis of Direct and Selected Indirect Subsides to Coal Electricity Production in the Energy Community Contracting Parties, www.energy-community.org (accessed: 2019)

[14] A. Avdic, T. Konjic, N. Dautbasic, "Auxiliary Power Systems of Advanced Thermal Power Plants", Advanced Technologies, Systems, and Applications IV - Proceedings of the International Symposium on Innovative and Interdisciplinary Applications of Advanced Technologies (IAT 2019), volume 83, 2019, pp. 117-125 